\title{
Female sexual dysfunction in androgenetic alopecia: Case-control study
}

\author{
Eyup Burak Sancak, MD;' Sevilay Oguz, MD; ${ }^{2}$ Tugba Akbulut, MD; ${ }^{3}$ Aysegul Uludag, MD;4 \\ Alpaslan Akbas, MD;' Omer Kurt, MD; ${ }^{5}$ Mehmet Fatih Akbulut, MD ${ }^{6}$
}

'Department of Urology, Canakkale Onsekiz Mart University, Faculty of Medicine, Canakkale, Turkey; ${ }^{2}$ Department of Dermatology, Canakkale Onsekiz Mart University, Faculty of Medicine, Canakkale, Turkey; ${ }^{3}$ Department of Dermatology, Haseki Training and Research Hospital, Istanbul, Turkey; ${ }^{4}$ Department of Family Medicine, Canakkale Onsekiz Mart University, Faculty of Medicine, Canakkale, Turkey; ${ }^{5}$ Department of Urology, Namık Kemal University, Faculty of Medicine, Tekirdag, Turkey; ${ }^{6}$ Department of Urology, Haseki Training and Research Hospital, Istanbul, Turkey

Cite as: Can Urol Assoc J 2016;10(7-8):E251-6. http://dx.doi.org/10.5489/cuaj.3582

Published online July 12, 2016

\section{Abstract}

Introduction: We sought to evaluate the association of female sexual dysfunction (FSD) with androgenetic alopecia (AGA) and metabolic syndrome (MetS) in premenopausal women.

Methods: From December 2013 to June 2015, we performed a case-control, prospective study of 115 patients with AGA and 97 age-matched control patients without AGA from among premenopausal women who visited dermatology clinics of the two reference hospitals. Comprehensive history, anthropometric measurements, and questionnaire administration were performed for each of the total of 212 women. The Female Sexual Function Index (FSFI) was used to assess the key dimensions of female sexual function. AGA was assessed and graded by an experienced dermatologist according to Ludwig's classification. The MetS assessment was made according to the NCEP-ATP III criteria.

Results: In univariate analysis, age, weight, waist circumference, hip circumference, waist-to-hip ratio, body mass index (BMI), AGA, MetS, cardiovascular event, marital status, hypertension, high fasting plasma glucose, high triglyceride, large waist, total testosterone, and free testosterone were associated with presence of FSD. In logistic regression analysis, age (odds ratio [OR] 1.21, 95\% confidence interval [CI] 1.13-1.30; $\mathrm{p}<0.001)$, AGA (OR 3.42, 95\% Cl 1.31-8.94; $p=0.017$ ), MetS (OR 5.39, 95\% Cl 1.34-21.62; $\mathrm{p}=0.012$ ), and free testosterone (OR 0.18, 95\% Cl 0.09-0.37; $\mathrm{p}<0.001)$ were independently associated with FSD.

Conclusions: Our study suggests that age, AGA, MetS, and free testosterone may have strong impact on sexual function in premenopausal women. Further studies with population-based and longitudinal design should be conducted to confirm this finding.

\section{Introduction}

According to the definition of the World Health Organization, sexual health is a state of physical, emotional, mental and social well-being in relation to sexuality. ${ }^{1}$ Damaged sexual health can have a major impact on quality of life. ${ }^{2}$ Despite the high prevalence of female sexual dysfunction (FSD), detailed knowledge of pathogenesis is still not adequately understood. Hormonal factors, chronic medical diseases, and psychosocial factors affecting women's sexuality are thought to play an important role in the formation of FSD. ${ }^{3,4}$ The most important hormones in the etiopathogenesis of FSD are undoubtedly androgens. ${ }^{3,5,6}$ Among the various determinants of FSD, metabolic syndrome (MetS) is an emerging concern, owing to its high and increasing prevalence. ${ }^{4,7,8}$

Female androgenetic alopecia (AGA) typically presents as diffuse reduction of hair thickness and density of frontoparietal and crown areas of the scalp, with preservation of the frontal hairline. Although the distribution of hair loss in female AGA is usually different from that seen in male AGA, the histopathological changes are similar. ${ }^{9,10}$ A complicated relationship between genetic predisposition and androgens is responsible for the etiopathogenesis. The prevalence of MetS in AGA patients is high and it is stated that early interventions for MetS patients with AGA can reduce later-developing complications. ${ }^{11,12}$

While MetS has a negative effect on both AGA and FSD, androgens are important hormones, playing a role in the formation of both AGA and FSD. Evaluation of the relationship between AGA and FSD, in addition to researching the role of MetS, will contribute significantly to understanding the etiopathogenesis of these diseases. Ultimately, we aim to evaluate the association of FSD with AGA and MetS in premenopausal women.

\section{Methods}

\section{Sample and design}

Our study included female patients with AGA and agematched female control patients without AGA who met the 
inclusion criteria, applying to dermatology clinics of two reference hospitals (Canakkale Onsekiz Mart University Hospital and Istanbul Haseki Training and Research Hospital) between December 2013 and June 2015. In this prospective study, each participant signed an informed consent form in accordance with the Declaration of Helsinki, and this study was approved by the Research and Ethical Review Board of Canakkale Onsekiz Mart University. Women were eligible for inclusion if they were over 18 years old and premenopausal, with a regular menstrual cycle. Exclusion criteria included a history of malignancy, diagnosis of psychological disorders, other types of alopecia, and previous treatment for hair loss. Participants were also excluded if they had received any current or recent (one year) hormone replacement treatment, antidepressants, anxiolytics, neuroleptics, or corticosteroid therapy that might interfere with sexuality, or if they had polycystic ovary syndrome (PCOS).

We planned our study with continuous response variables from independent control and experimental subjects with one control(s) per experimental subject. We reached 115 patients in the AGA group and 97 patients in the control group, with over 0.90 power.

\section{Clinical and biochemical assessment}

Detailed anamneses were recorded for each individual and physical examinations were performed. Demographic characteristics, family history of hair loss (maternal or paternal heredity), previous cardiovascular events (coronary artery disease and congestive heart failure), and type 2 diabetes mellitus (T2DM) were documented for each patient. The Ludwig classification was used to grade AGA by an experienced dermatologist. ${ }^{13}$ Height, weight, waist circumference, hip circumference, and neck circumference were measured. The BMI was calculated by dividing the weight by the square of height (kg/ $\mathrm{m}^{2}$ ) and the waist-to-hip ratio (WHR) was calculated. For categorical assessment of waist-to-hip ratio, 0.85 was accepted as the cutoff value. Blood pressure was measured on the right arm in a sitting position and after a 20-minute rest.

The triglyceride (TG), high-density lipoprotein (HDL), total testosterone $(\mathrm{ng} / \mathrm{ml})$, and fasting plasma glucose (FPG; $\mathrm{mg} / \mathrm{dL}$ ) levels measured by standard laboratory methods and free testosterone $(\mathrm{pg} / \mathrm{ml})$ levels measured by radioimmunoassay were scanned from the records. ${ }^{14}$ As it is the most commonly used definition reported in the literature, the 2004 National Cholesterol Education Program-Adult Treatment Panel (NCEP-ATP) III diagnosis criteria were used (waist circumference $\geq 88 \mathrm{~cm}$ [large waist], TG value $\geq 150 \mathrm{mg} / \mathrm{dl}$ [high TG], HDL $\leq 50 \mathrm{mg} / \mathrm{dl}$ [low HDL], arterial blood pressure $\geq 130 / 85 \mathrm{mmHg}$ [HT], FPG $\geq 100 \mathrm{mg} / \mathrm{dl}$ [high FPG] or T2DM). Patients with three or more positive criteria were considered to have MetS. ${ }^{15}$

\section{Sexual questionnaire}

A validated Turkish version of the Female Sexual Function Index (FSFI) was used to evaluate female sexual function. ${ }^{16,17}$ The highest points possible are 36.0, while the lowest points possible are 2.0, with higher score indicating better function. A cutoff individual domain score of 26.55 on the FSFI is the current standard for diagnosis of FSD. ${ }^{4,18,19} \mathrm{~A}$ score of less than the median value is considered to reflect sexual dysfunction for each particular domain. Therefore, sexual dysfunctions for each of the six specific domains are suggested as a desire score of $\leq 3.6$, an arousal score of $\leq 3.9$, a lubrication score of $\leq 5.4$, an orgasm score of $\leq 4.0$, a satisfaction score of $\leq 4.0$, and a pain score of 4.8 or less. ${ }^{20}$

\section{Statistical analysis}

Statistical analysis was performed with SPSS 20.0 statistical software package. All values are shown as mean \pm standard deviation for quantitative, and numbers and percentages for qualitative variables. The baseline characteristics of the groups with AGA and without AGA were compared using a T-test or Mann-Whitney U-test for continuous variables and a Chi-square test or Fisher's exact test for categorical variables. The Mann-Whitney U-test was also performed to test the significance of pairwise differences using Bonferroni correction to adjust for multiple comparisons. Similar analyses were completed for the groups with and without FSD. The potential risk factors identified from univariate analyses for FSD were further entered into the logistic regression analysis. Logistic regression analysis was used to calculate the odds ratio $(\mathrm{OR})$ and $95 \%$ confidence interval $(\mathrm{Cl})$ for occurrence of FSD. Hosmer-Lemeshow goodness of fit statistics were used to assess model fit. All statistical tests were two-tailed and statistical significance was defined as $\mathrm{p}<0.05$.

\section{Results}

The 115 women with AGA were matched with 97 women of the control group for age $(36.28 \pm 8.92 \mathrm{vs} .36 .07 \pm 9.00$ years; $\mathrm{p}=0.868$ ) and premenopausal state. The rates of FSD and MetS were $44.8 \%(95 / 212)$ and $19.8 \%(42 / 212)$ in all subjects. The study subjects' general characteristics are shown in Table 1 . While $24.3 \%$ of women with AGA had MetS, $14.4 \%$ of the control group had MetS $(p=0.071)$. There was a significant difference found between the married and single groups in terms of AGA $(p=0.014)$.

The relationship between FSD with MetS and AGA is depicted in an error graph (Fig. 1). The FSFI score in the AGA patient group was calculated as $23.19 \pm 4.95$ for those with MetS and $25.84 \pm 7.53$ for those without MetS $(p=0.036)$. In the control group, the FSFI score was calculated as 22.59 \pm 7.18 for patients with MetS and $28.39 \pm 4.84$ for patients 


\begin{tabular}{|c|c|c|c|}
\hline Variables & $\begin{array}{l}\text { Female androgenetic alopecia } \\
\qquad(\mathrm{n=115)}\end{array}$ & $\begin{array}{c}\text { Controls } \\
(n=97)\end{array}$ & p value* \\
\hline No. patients (\%) & $115(21.1)$ & 97 (78.9) & \\
\hline Age (years) (mean \pm SD) & $36.28 \pm 8.92$ & $36.07 \pm 9.00$ & 0.868 \\
\hline $\begin{array}{l}\text { Occupation (\%) } \\
\text { Housewife } \\
\text { Officer } \\
\text { Worker } \\
\text { Student } \\
\text { Retired/unemployed }\end{array}$ & $\begin{array}{c}66(57.4) \\
20(17.4) \\
13(11.3) \\
4(3.5) \\
12(10.4)\end{array}$ & $\begin{array}{c}57(58.8) \\
22(22.7) \\
6(6.2) \\
2(2.1) \\
10(9.7)\end{array}$ & 0.591 \\
\hline $\begin{array}{l}\text { Marital status (\%) } \\
\text { Married } \\
\text { Single } \\
\text { Divorced/separated }\end{array}$ & $\begin{array}{c}98(85.2) \\
15(10.4) \\
2(1.7)\end{array}$ & $\begin{array}{c}76(78.4) \\
12(12.4) \\
9(9.3)\end{array}$ & $0.049 * *$ \\
\hline Family history (\%) & $46(40.0)$ & $10(10.3)$ & $<0.001$ \\
\hline Cardiovascular event (\%) & $10(8.7 \%)$ & $8(8.2)$ & 0.907 \\
\hline Height $(\mathrm{cm})($ mean \pm SD) & $161.70 \pm 6.02$ & $161,87 \pm 5.54$ & 0.986 \\
\hline Weight $(\mathrm{kg})($ mean $\pm \mathrm{SD})$ & $70.46 \pm 15.85$ & $65.25 \pm 10.06$ & 0.030 \\
\hline Waist circumference (mean $\pm \mathrm{SD}$ ) & $90.42 \pm 13.46$ & $82.73 \pm 10.81$ & $<0.001$ \\
\hline Hip circumference (mean \pm SD) & $106.99 \pm 10.10$ & $100.25 \pm 10.79$ & $<0.001$ \\
\hline Neck circumference (mean \pm SD) & $33.54 \pm 3.89$ & $33.94 \pm 2.78$ & 0.416 \\
\hline Waist to hip ratio (mean \pm SD) & $0.84 \pm 0.07$ & $0.82 \pm 0.06$ & 0.034 \\
\hline Body mass index (mean $\pm S D$ ) & $26.94 \pm 5.81$ & $24.92 \pm 3.80$ & 0.009 \\
\hline High FPG (\%) & $17(14.8)$ & $7(7.2)$ & 0.083 \\
\hline Hypertension (\%) & $32(27.8)$ & $16(16.5)$ & 0.050 \\
\hline Large waist (\%) & $67(58.3)$ & $34(35.1)$ & 0.001 \\
\hline High TG (\%) & $20(17.4)$ & $7(7.2)$ & 0.027 \\
\hline Low HDL (\%) & $64(55.7)$ & $63(64.9)$ & 0.169 \\
\hline Metabolic syndrome (\%) & $28(24.3)$ & $14(14.4)$ & 0.071 \\
\hline Total testosterone (mean $\pm \mathrm{SD}$ ) & $0.38 \pm 0.19$ & $0.36 \pm 0.19$ & 0.461 \\
\hline Free testosterone (mean \pm SD) & $1.70 \pm 0.83$ & $0.32 \pm 0.12$ & 0.041 \\
\hline FSFI score (mean \pm SD) & $25.43 \pm 6.88$ & $27.55 \pm 5.58$ & 0.047 \\
\hline Female sexual dysfunction (\%) & $60(52.2)$ & $35(36.1)$ & 0.019 \\
\hline Desire disorder (\%) & $62(53.9)$ & $26(26.8)$ & $<0.001$ \\
\hline Arousal disorder (\%) & $35(30.4)$ & $17(17.5)$ & 0.030 \\
\hline Lubrication disorder (\%) & $47(40.9)$ & $32(32.9)$ & 0.237 \\
\hline Orgasmic disorder $(\%)$ & $48(41.7)$ & 32 (32.9) & 0.237 \\
\hline Satisfaction disorder (\%) & $42(36.5)$ & $26(26.8)$ & 0.131 \\
\hline Sexual pain disorder (\%) & $40(34.8)$ & $41(42.3)$ & 0.264 \\
\hline
\end{tabular}

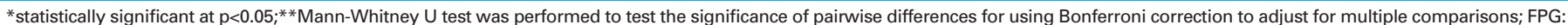
fasting plasma glucose HDL: high-density lipoprotein; SD: standard deviation; TG: trigyceride.

without MetS ( $p=0.004)$ (Table 2). In AGA patients without MetS, FSD was observed at a rate of $41.3 \%$, while in those with MetS, this rate increased to $85.7 \%(p<0.001)$.

The factors with statistically significant difference identified on univariate analysis were included in logistic regression analysis using the enter method. On logistic regression, age (OR 1.21, 95\% Cl 1.13-1.30; $\mathrm{p}<0.001)$, AGA (OR 3.42, 95\% Cl 1.31-8.94; $\mathrm{p}=0.017$ ), MetS (OR 5.39, 95\% Cl 1.34-21.62; $\mathrm{p}=0.012$ ), and free testosterone (OR 0.18, $95 \% \mathrm{Cl} 0.09-0.37 ; \mathrm{p}<0.001)$ were independently associated with FSD (Table 3).

\section{Discussion}

Here, we present the results of the first case-control study evaluating the impact of AGA on female sexual function in premenopausal women. We found that female sexual function is significantly compromised by the presence of AGA. It was also evident that a MetS is associated with a greater risk of FSD.

FSD can have a major impact on quality of life. Damaged sexual function has debilitating effects on self-esteem and interpersonal relationships of women. ${ }^{2}$ A national survey study of people aged $18-59$ years reported $43 \%$ of women 


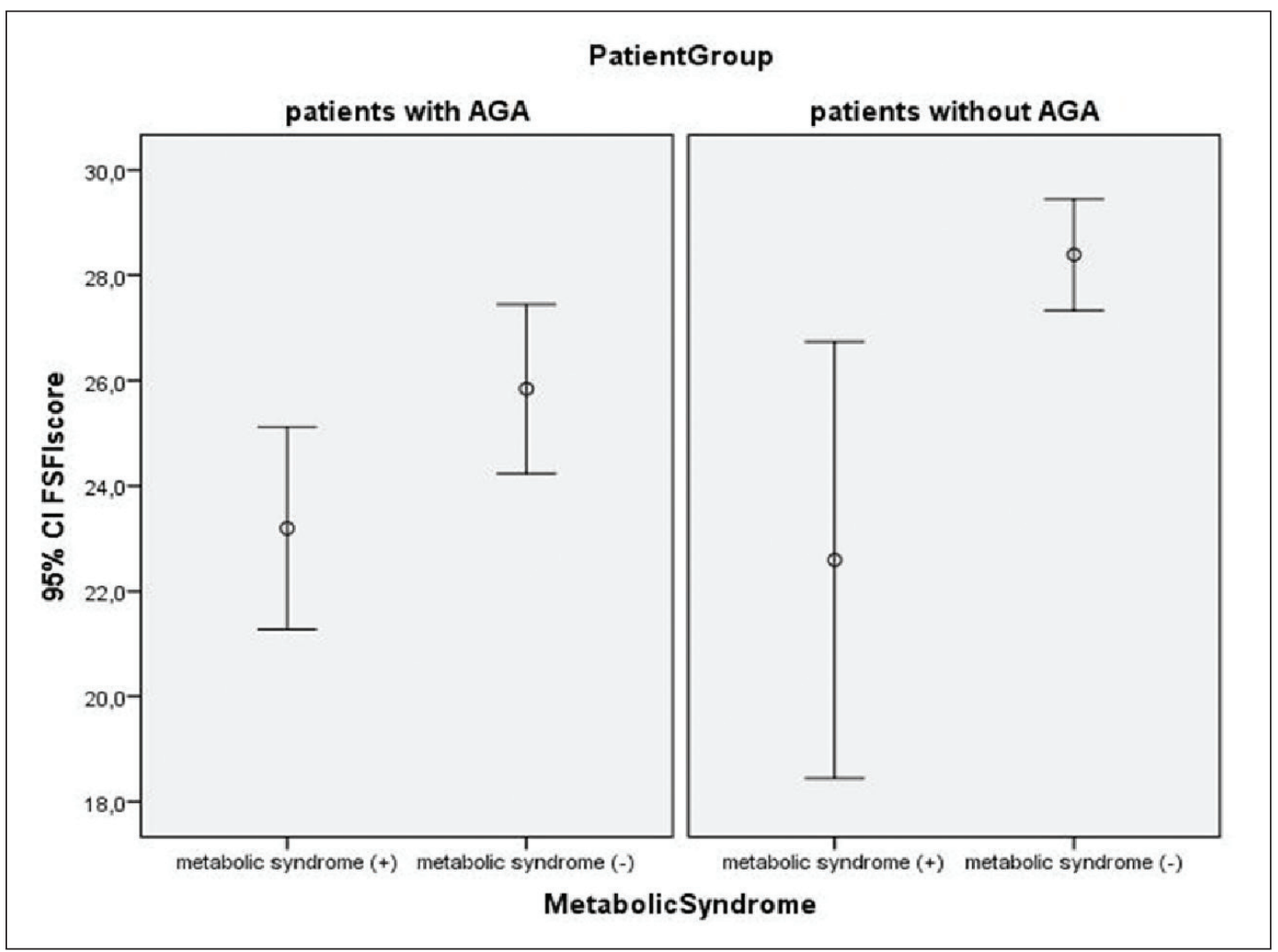

Fig. 1. The relationship between Female Sexual Function Index (FSFI) scores with metabolic syndrome (MetS) and androgenetic alopecia (AGA).

had FSD. ${ }^{21}$ A study of 179 Turkish women aged from 18 to 66 years found the prevalence of FSD was $46.9 \% .^{22}$ In our study, in accordance with the literature, the prevalence of FSD was $44.8 \%$ in premenopausal women between 18-53 years old. Despite the high prevalence, FSD pathogenesis is still not adequately understood. Though the common etiopathogenesis of FSD and AGA includes androgens, HT, cardiac diseases, insulin resistance, and MetS, to date there is no study found researching the relationship between FSD and AGA. ${ }^{11}$

AGA is the most common form of alopecia in both sexes, but its pathogenic mechanisms have been mostly studied in men. ${ }^{23}$ Several anthropometric factors associated with female AGA in previous reports were predictors of female AGA. ${ }^{11,12,23}$

Table 2. The relationship of AGA, MetS, and female sexual function

\begin{tabular}{|c|c|c|c|c|c|c|c|c|c|c|}
\hline & \multicolumn{4}{|c|}{ Androgenetic alopecia $n=115$} & \multicolumn{4}{|c|}{ Control n=97 } & \multirow[b]{2}{*}{ Total } & \multirow[b]{2}{*}{$\begin{array}{c}\mathbf{p} \\
\text { value }^{* *}\end{array}$} \\
\hline & Total & $\begin{array}{c}\text { Metabolic } \\
\text { syndrome (+) } \\
n=28\end{array}$ & $\begin{array}{c}\text { Metabolic } \\
\text { syndrome } \\
(-) \\
n=87\end{array}$ & $\begin{array}{c}\text { p } \\
\text { value* }\end{array}$ & Total & $\begin{array}{c}\text { Metabolic } \\
\text { syndrome } \\
(+) \\
n=14\end{array}$ & $\begin{array}{c}\text { Metabolic } \\
\text { syndrome } \\
(-) \\
n=83\end{array}$ & $\begin{array}{c}\text { p } \\
\text { value* }\end{array}$ & & \\
\hline FSD (\%) & $60(52.2)$ & $24(85.7)$ & $36(41.3)$ & $<0.001$ & $35(36.1)$ & $11(78.5)$ & $24(28.9)$ & $<0.001$ & $95(44.8)$ & 0.019 \\
\hline FSFI score & $25.19 \pm 7.06$ & $23.19 \pm 4.95$ & $25.84 \pm 7.53$ & 0.036 & $27.55 \pm 5.58$ & $22.59 \pm 7.18$ & $28.39 \pm 4.8$ & 0.004 & $26.27 \pm 6.53$ & 0.047 \\
\hline Desire score & $3.06 \pm 0.98$ & $2.83 \pm 0.90$ & $3.14 \pm 1.01$ & 0.142 & $3.56 \pm 1.02$ & $2.95 \pm 1.25$ & $3.65 \pm 0.94$ & 0.017 & $3.29 \pm 1.03$ & $<0.001$ \\
\hline Arousal score & $4.90 \pm 1.82$ & $4.42 \pm 1.49$ & $5.05 \pm 1.89$ & 0.112 & $5.27 \pm 1.74$ & $4.38 \pm 2.03$ & $5.42 \pm 1.65$ & 0.040 & $5.06 \pm 1.78$ & 0.189 \\
\hline $\begin{array}{l}\text { Lubrication } \\
\text { score }\end{array}$ & $5.71 \pm 1.93$ & $5.21 \pm 1.55$ & $5.87 \pm 2.01$ & 0.116 & $6.12 \pm 1.78$ & $4.95 \pm 2.12$ & $6.32 \pm 1.65$ & 0.035 & $5.90 \pm 1.87$ & 0.136 \\
\hline Orgasm score & $3.67 \pm 1.16$ & $3.54 \pm 1.09$ & $3.71 \pm 1.19$ & 0.485 & $4.00 \pm 0.92$ & $3.30 \pm 1.18$ & $4.12 \pm 0.82$ & 0.002 & $3.82 \pm 1.07$ & 0.096 \\
\hline $\begin{array}{l}\text { Satisfaction } \\
\text { score }\end{array}$ & $3.85 \pm 1.13$ & $3.70 \pm 1.01$ & $3.90 \pm 1.16$ & 0.416 & $4.07 \pm 0.91$ & $3.22 \pm 1.17$ & $4.22 \pm 0.77$ & 0.008 & $3.95 \pm 1.04$ & 0.262 \\
\hline Pain & $4.09 \pm 1.22$ & $3.70 \pm 1.02$ & $4.21 \pm 1.25$ & 0.055 & $4.08 \pm 1.23$ & $3.69 \pm 1.11$ & $4.14 \pm 1.23$ & 0.202 & $4.09 \pm 1.22$ & 0.626 \\
\hline
\end{tabular}

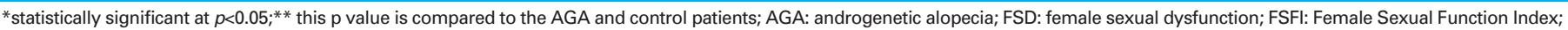
MetS: metabolic syndrome. 
Female sexual function and alopecia

Table 3. The association of FSD with patient demographics, cardiovascular risk factors, clinical variables, and AGA

\begin{tabular}{|c|c|c|c|c|c|c|}
\hline & \multicolumn{3}{|c|}{ Univariate analysis } & \multicolumn{3}{|c|}{ Logistic regression analysis } \\
\hline & OR & $95 \% \mathrm{Cl}$ & p value* & OR & $95 \% \mathrm{Cl}$ & p value* \\
\hline Age (years) & 1.17 & $1.12-1.22$ & $<0.001$ & 1.21 & $1.13-1.30$ & $<0.001$ \\
\hline Height (cm) & 0.97 & $0.92-1.02$ & 0.183 & & & \\
\hline Weight (kg) & 1.03 & $1.00-1.05$ & 0.011 & & & \\
\hline Waist circumference & 1.05 & $1.02-1.07$ & $<0.001$ & & & \\
\hline Hip circumference & 1.03 & $1.00-1.06$ & 0.009 & & & \\
\hline Neck circumference & 1.04 & $0.96-1.13$ & 0.287 & & & \\
\hline WHR $\geq 0.85$ & 1.89 & $1.09-3.29$ & 0.024 & & & \\
\hline BMI & 1.09 & $1.03-1.16$ & 0.002 & & & \\
\hline Alopecia & 1.93 & $1.11-3.36$ & 0.019 & 3.42 & $1.31-8.94$ & 0.017 \\
\hline CVE & 3.55 & $1.22-10.35$ & 0.020 & & & \\
\hline Metabolic syndrome & 5.27 & $1.33-20.92$ & $<0.001$ & 5.39 & $1.34-21.62$ & 0.012 \\
\hline Occupation** & 1.43 & $0.79-2.58$ & 0.233 & & & \\
\hline Marital status ${ }^{* * *}$ & 2.29 & $1.07-4.90$ & 0.033 & & & \\
\hline HT & 3.20 & $1.63-6.31$ & 0.001 & & & \\
\hline High FPG & 2.75 & $1.12-6.76$ & 0.022 & & & \\
\hline Large waist & 3.17 & $1.80-5.58$ & $<0.001$ & & & \\
\hline High TG & 3.40 & $1.42-8.18$ & 0.004 & & & \\
\hline Low HDL & 0.66 & $0.38-1.16$ & 0.152 & & & \\
\hline Total testosterone & 1.83 & $0.45-7.51$ & 0.047 & & & \\
\hline Free testosterone & 0.365 & $0.2-0.57$ & $<0.001$ & 0.18 & $0.09-0.37$ & $<0.001$ \\
\hline
\end{tabular}

In our study, the difference between AGA and MetS was not significant, though this may be due to the fact that our study was not a population-based study. However, a statistically significant association was found between AGA and the components of MetS of HT, large waist, and high TG.

Total testosterone is the sum of sex hormone-binding globulin-bound testosterone, other proteins bounding testosterone (mainly albumin), and free testosterone. Because only free testosterone and albumin-bound testosterone are bioavailable, serum total testosterone level might not reflect the exact testosterone function. ${ }^{14}$ In our study, despite excluding patients receiving hormone replacement therapy, those with irregular menstrual cycle, and PCOS patients, there was no significant difference between patients with and without AGA in terms of total testosterone; however, there was a significant difference in terms of free testosterone. In the literature, there are limited studies comparing free testosterone values in female AGA patients. ${ }^{24}$

The mean FSFI score in female patients with AGA was $25.43 \pm 6.88$; this score was $27.55 \pm 5.58$ for the control group ( $p=0.047$ ). While FSD was observed in $52.2 \%$ of AGA patients, the rate was $36.1 \%$ for those without AGA $(p=0.019)$. When both groups are compared in terms of specific domains, the desire and arousal disorder rates were observed to be higher for patients with AGA.

The relationship of FSD to AGA and MetS is summarized in Table 2. In the AGA group, the total FSFI score of those without MetS was $25.84 \pm 7.53$, while the total FSFI score was calculated as $28.39 \pm 4.84$ for those in the control group without MetS. The reason for this may be due to the negative effect of AGA on female sexual function.

Many parameters that may affect female sexual function were assessed with univariate analysis and results are presented in Table 3. Previous studies have assessed a variety of risk factors that may affect FSD. A web-based survey of 504 young Korean women by Song et al found that risk factors for FSD were increasing age, low frequency of sex, depression, history of sexual abuse, and voiding dysfunction according to logistic regression analysis. ${ }^{20}$ According to a cross-sectional, questionnaire-based study of middleaged women by Cabral et al, there was a significant association between sexual function and age group, education, marital status, menopausal status, hysterectomy, levels of physical activity, quality of life, and menopause symptoms. They found no significant difference in terms of race, family income, and smoking. ${ }^{18}$

In our study, age, MetS, and AGA were independent risk factors for FSD, while free testosterone was a protective factor. In addition, it is especially necessary to assess MetS patients with AGA for FSD. Further investigation in women of the role of hormones, ischemia, inflammation, and psychosocial situation on the development of FSD in patients with MetS and/or AGA is critical for the understanding of this association. 
Sancaket al.

Our study suggests that age, AGA, MetS, and free testosterone may have strong impact on sexual function in premenopausal women. Further studies with population-based and longitudinal design should be conducted to confirm this finding.

The limitations of the current study are the hospital-based, case-control design and small size, limiting the ability to describe causal relationships of the associations detected. Although participants who visited the two reference hospitals do not represent an exact general population, they could possess characteristics much closer to those of the general population than patient groups used in previous investigations. It is possible that women who sought out a dermatologist could have more psychological symptoms than those who did not. Lastly, we could not control other possible confounders, including education level, family income, lower urinary tract symptoms, psychological variables (such as body image), and interpersonal variables (such as relationship with a partner). These unconsidered factors should be taken into account in further studies.

Competing interests: The authors declare no competing personal or financial interests.

This paper has been peer-reviewed.

\section{References}

1. Organization WH. Defining sexual health: Report of a technical consultation on sexual health, 28-31 January 2002, Geneva: World Health Organization; 2006.

2. Jaafarpour M, Khani A, Khajavikhan J, et al. Female sexual dysfunction: Prevalence and risk factors. J Clin Diagn Res 2013;7:2877-80.

3. Pluchino N, Carmignani A, Cubeddu A, et al. Androgen therapy in women: For whom and when. Arch Gynecol Obstet 2013;288:731-7. http://dx.doi.org/10.1007/s00404-013-2969-7

4. Kim YH, Kim SM, Kim JJ, et al. Does metabolic syndrome impair sexual function in middle- to old-aged women? I Sex Med 2011;8:1123-30. http://dx.doi.org/10.1111/j.1743-6109.2010.02174.x

5. Davis S. Androgen replacement in women: A commentary. J Clin Endocrinol Metab 1999;84:1886-91. http://dx.doi.org/10.1210/icem.84.6.5802

6. Hubayter Z, Simon JA. Testosterone therapy for sexual dysfunction in postmenopausal women. Climacteric 2008;11:181-91. http://dx.doi.org/10.1080/13697130802162822
7. Ponholzer A, Temml C, Rauchenwald $M$, et al. Is the metabolic syndrome a risk factor for female sexual dysfunction in sexually active women? Int I Impot Res 2008;20:100-4. http://dx.doi.org/10.1038/ si.jiir.3901605

8. Borges R, Temido P, Sousa L, et al. Metabolic syndrome and sexual (dys)function. J Sex Med 2009;6:2958-75. http://dx.doi.org/10.1111/i.1743-6109.2009.01412.x

9. Glaser RL, Dimitrakakis C, Messenger AG. Improvement in scalp hair growth in androgen-deficient women treated with testosterone: A questionnaire study. Br J Dermatol 2012;166:274-8. http:// dx.doi.org/10.1111/i.1365-2133.2011.10655.x

10. Valente Duarte de Sousa IC, Tosti A. New investigational drugs for androgenetic alopecia. Expert Opin Investig Drugs 2013;22:573-89. http://dx.doi.org/10.1517/13543784.2013.784743

11. Su LH, Chen TH. Association of androgenetic alopecia with metabolic syndrome in men: A community-based survey. Br J Dermatol 2010;163:371-7. http://dx.doi.org/10.1111/j.1365-2133.2010.09816.x

12. Acibucu $F$, Kayatas $M$, Candan $F$. The association of insulin resistance and metabolic syndrome in early androgenetic alopecia. Singapore Med J 2010;51:931-6.

13. Ludwig E. Classification of the types of androgenetic alopecia (common baldness) occurring in the female sex. Br J Dermatol 1977;97:247-54. http://dx.doi.org/10.1111/j.1365-2133.1977.tb15179.x

14. Okamura K, Ando F, Shimokata H. Serum total and free testosterone level of Japanese men: A populationbased study. Int I Urol 2005;12:810-4. http://dx.doi.org/10.1111/j.1442-2042.2005.01143.x

15. Rostom $S$, Mengat $M$, Lahlou $R$, et al. Metabolic syndrome in rheumatoid arthritis: Case-control study. BMC Musculoskelet Disord 2013;14:1471-2474. http://dx.doi.org/10.1186/1471-2474-14-147

16. Rosen R, Brown C, Heiman J et al. The Female Sexual Function Index (FSFI): A multidimensional selfreport instrument for the assessment of female sexual function. J Sex Marital Ther 2000;26:191-208. http://dx.doi.org/10.1080/009262300278597

17. Aygin D, Aslan FE. The Turkish adaptation of the female sexual function index. Turkiye Klinikleri Journal of Medical Sciences 2005;25:393.

18. Cabral PU, Canario AC, Spyrides MH, et al. Determinants of sexual dysfunction among middle-aged women. Int J Gynaecol Obstet 2013;120:271-4. http://dx.doi.org/10.1016/i.i.igo.2012.09.023

19. Wiegel M, Meston C, Rosen R. The female sexual function index (FSFI): Cross-validation and development of clinical cutoff scores. J Sex Marital Ther 2005;31:1-20. http://dx.doi. org/10.1080/00926230590475206

20. Song SH, Jeon $\mathrm{H}$, Kim SW, et al. The prevalence and risk factors of female sexual dysfunction in young korean women: An internet-based survey. J Sex Med 2008;5:1694-701. http://dx.doi.org/10.1111/ j. $1743-6109.2008 .00840 . x$

21. Laumann EO, Paik A, Rosen RC. Sexual dysfunction in the United States: prevalence and predictors. JAMA 1999;281:537-44. http://dx.doi.org/10.1001/jama.281.6.537

22. Cayan S, Akbay E, Bozlu M, et al. The prevalence of female sexual dysfunction and potential risk factors that may impair sexual function in Turkish women. Urol Int 2004;72:52-7. http://dx.doi. org/10.1159/000075273

23. Matilainen V, Laakso M, Hirsso $P$, et al. Hair loss, insulin resistance, and heredity in middle-aged women. A population-based study. J Cardiovasc Risk 2003;10:227-31. http://dx.doi.org/10.1097/01. hir.0000070200.72977.c6

24. Levy LL, Emer JJ. Female pattern alopecia: Current perspectives. Int J Womens Health 2013:5:541-56.

Correspondence: Dr. Eyup Sancak, Department of Dermatology, Canakkale Onsekiz Mart University, Faculty of Medicine, Canakkale, Turkey; eyupburaksancak@comu.edu.tr 